\title{
Exposure Reported Name of Treatment
}

National Cancer Institute

\section{Source}

National Cancer Institute. Exposure Reported Name of Treatment. NCI Thesaurus. Code C83091.

The literal identifier of an exposure treatment. 